\title{
Stimulus intensity and trace intervals in sensory preconditioning using the CER
}

\author{
JOHN D. ROGERS \\ California State University, San Jose, Calif. 95114
}

Sixty-four rats were given preconditioning training $\left(S_{1}-S_{2}\right.$ pairings) with a trace interval of $0,2,5$, or 8 sec and an $S_{1}$ of either strong or mild intensity. Preconditioning was followed by conditioned emotional response (CER) training, with $\mathrm{S}_{2}$ used as a CS. The response measure used for analysis was the suppression of consummatory drinking in the presence of $S_{1}$. The results indicated: (a) a significantly greater amount of suppression for strong $S_{1}$ groups than for mild $S_{1}$ groups, (b) no significant differences in suppression among groups receiving various trace-interval lengths, and (c) no significant interaction effects. It was concluded that the results were similar to effects obtained in comparable classical conditioning situations.

The sensory preconditioning (SPC) paradigm may be divided into three phases. In the preconditioning phase, two neutral stimuli $\left(S_{1}\right.$ and $\left.S_{2}\right)$ from different sensory modalities are repeatedly presented in close temporal contiguity. In the conditioning phase, an overt CR is established to $S_{2}$. The third phase consists of a test for transfer of the CR to $S_{1}$.

The SPC phenomenon can be interpreted as a form of S-R learning by invoking a mediational hypothesis (Osgood, 1953). In the mediation hypothesis, the preconditioning phase is treated as a classical conditioning paradigm, with $S_{1}$ corresponding to a CS and $S_{2}$ corresponding to a mild US. During preconditioning, a covert UR elicited by $S_{2}$ becomes conditioned to $S_{1}$. In the conditioning phase, $S_{2}$ becomes a CS, produces a UR, and the sensory feedback from that response also becomes a part of the stimulation to which the measured response (overt CR) is conditioned. In the test phase, $S_{1}$ elicits the covert $\mathrm{CR}$ acquired during preconditioning and the sensory feedback from this response elicits the overt $\mathrm{CR}$.

An implication of the mediation hypothesis is that variable manipulations known to affect CR magnitude in classical conditioning should have a similar influence on the strength of the covert CR acquired during preconditioning. Several variables of importance in classical conditioning have been investigated within the SPC framework. For example, Prewitt (1967) examined the function of the number of preconditioning trials on SPC; Tait, Marquis, Williams, Weinstein, \& Suboski (1969) examined the function of the number of extinction presentations of $S_{1}$ following preconditioning on SPC and the effect of forward and backward preconditioning on SPC; Tait, Black, Katz, \& Suboski (1972) investigated the effect of preconditioning discrimination training on SPC. Despite the fact that, in SPC, covert CR strength must be measured indirectly from the amount of response transfer, the results of these studies generally indicate that SPC and classical conditioning are similarly responsive to the manipulation of comparable variables.

Little attention has been given to the effect of variations of a preconditioning trace interval (i.e., an interval between $S_{1}$ offset and $S_{2}$ onset) on performance. In addition, the evidence regarding the effect of $S_{1}$ intensity variations on performance seems to be equivocal (e.g., Holmes, 1968; Tait \& Suboski, 1972; Thornton, 1958; Wokoum, 1959). The present study was designed to compare the effects of the above variables with those of classical conditioning in similar parametric experiments. If preconditioning is a form of classical conditioning, then the amount of transfer should vary inversely with the length of the trace interval (Kamin, 1961), and an increase in $S_{1}$ intensity should produce an increase in the amount of transfer (Gormezano \& Moore, 1969). Also, there seems little reason to believe the $S_{1}$ intensity effect will not be independent of the trace-interval factor.

\section{METHOD \\ Subjects}

The Ss were 64 male Sprague-Dawley rats, 80 days old and $380-430 \mathrm{~g}$ in weight at the onset of the experiment. All Ss were individually housed and were allowed free access to food.

\section{Apparatus}

The apparatus for preconditioning and conditioning consisted of a $9 \frac{1}{2} \times 8 \times 7 \frac{1}{2}$ in. conditioning chamber, mounted inside a Scientific Prototype A-115 sound-attenuated box. The chamber had front and rear walls of aluminum, side walls and lid of Plexiglas, and a floor of $1 / 8$-in. stainless steel grids on 9/16-in. centers. The scrambled electric shock delivered through the grids was generated by an A-615 Lafayette shock supply. A frosted 6-W light, serving as $S_{2}$, was mounted on the front wall 6 in. above the grid floor.

The testing apparatus consisted of a $9 \times 7 \frac{1}{2} \times 8$ in. test chamber, mounted inside a Scientific Prototype A-115 sound-attenuated box. The chamber had three walls (front, rear, and side) of white acrylic plastic, one side wall and lid of Plexiglas, and a stainless steel sheet floor. The spout of a water bottle was exposed through an opening in the front wall, $2 \frac{1 / 2}{2}$ in. above the floor. Each tongue contact with the water was relayed through a Grason-Stadler electronic drinkometer and recorded on a BRS Foringer printout counter.

The $S_{1}$ was presented by means of a Lafayette 15010 audio-signal generator and amplifier. Duration of stimuli, trace intervals, and ITIs were regulated by repetitively connected Hunter timers. In each sound-attenuating box, a fan produced a background noise level of $73 \mathrm{~dB}$, while a $6-\mathrm{W}$ light provided ambient illumination. The lids of the conditioning and test chambers were covered with manila paper so as to make the lighting more diffuse. All sound-level measures were taken with a General Radio sound-survey meter.

\section{Procedure}

Eight Ss were assigned randomly to the cells of a 2 by 4 


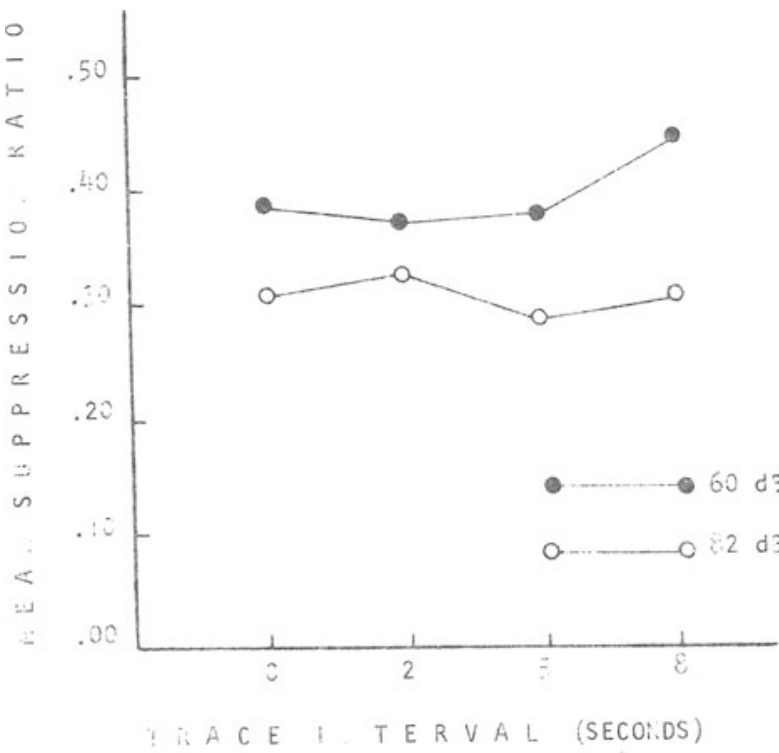

Fig. 1. Mean suppression ratios for groups given either a strong $S_{1}$ or a mild $S_{1}$ as a function of the length of the trace interval.

factorial design. The $S_{1}$ intensity factor was varied at two levels: $1000-\mathrm{cps} 82-\mathrm{dB}$ tone and $1000-\mathrm{cps} 60-\mathrm{dB}$ tone. The trace-interval factor was varied at four levels: $0,2,5$, and $8 \mathrm{sec}$.

In this experiment, Prewitt's (1967) CER procedure was used. After handling, Ss were water deprived for $24 \mathrm{~h}$ and then received water on two occasions in the test chamber. These lick sessions were $24 \mathrm{~h}$ apart and lasted for $700 \mathrm{sec}$ following the first burst of licking.

Preconditioning began $24 \mathrm{~h}$ after the second lick session. Sixteen $S_{1}-S_{2}$ (tone-light) pairings were given with a randomly prearranged ITI of 40,60 , or $80 \mathrm{sec}$. With the ISI (i.e., the interval between $S_{1}$ onset and $S_{2}$ onset) held constant at $10 \mathrm{sec}$, the length of the trace interval was varied at the four levels. Therefore, $S_{1}$ was either $82 \mathrm{~dB}$ or $60 \mathrm{~dB}$ in intensity and 10,8 , 5 , or $2 \mathrm{sec}$ in duration. The $\mathrm{S}_{2}$ was $6 \mathrm{~W}$ in intensity and $10 \mathrm{sec}$ in duration.

The CER conditioning began $60 \mathrm{sec}$ after the preconditioning phase. Ten $\mathrm{S}_{2}$-US (light-footshock) pairings were given with a randomly prearranged ITI of 40,60 , or $80 \mathrm{sec}$. The $S_{2}$ was of the same intensity and duration used during preconditioning. The US was $1.2 \mathrm{~mA} \mathrm{RMS}$ in intensity and $.5 \mathrm{sec}$ in duration. The $\mathrm{S}_{2}$ and US terminated simultaneously. A 30-min recovery period in the home cage followed CER conditioning. Subsequent to the recovery period, $\mathrm{S}$ was placed in the test chamber for a final 700 -sec lick session.

The test for transfer began $24 \mathrm{~h}$ after the final lick session. Sixty seconds after the first burst of licking, $10 \mathrm{~S}_{1}$ (tone) presentations were given, with a duration of $10 \mathrm{sec}$ and a randomly prearranged ITI of 40,60 , or $80 \mathrm{sec}$. For each $S$, the intensity of $S_{1}$ presented on test trials was the same as that given during preconditioning.

\section{Response Measure}

The suppression effect was measured by computing a suppression ratio. This ratio was calculated for each $S$ by taking the number of licks during any $S_{1}$ presentation and dividing it by the number of licks in the $10 \mathrm{sec}$ immediately preceding $S_{1}$ onset plus licks during the $S_{1}$ presentation. When calculated in this fashion, smaller ratios indicate greater suppression.

\section{RESULTS AND DISCUSSION}

The results of this experiment are presented in Fig. 1.
Each point represents a mean suppression ratio for a group of eight Ss. It is clear from Fig. 1 that suppression was consistently greater for strong $S_{1}$ groups than for mild $S_{1}$ groups, whereas variations in the trace interval produced very little difference in suppression by $S_{1}$. Figure 1 also suggests that the two factors function independently of each other. An analysis of variance conducted on the suppression ratios indicated that the strong $S_{1}$ groups showed significantly more suppression than the mild $S_{1}$ groups $(F=14.23, \quad d f=1 / 56$, $\mathrm{p}<.001$ ), while no other $\mathrm{F}$ ratio approached significance.

In classical conditioning, most reviewers (e.g., Gormezano \& Moore, 1969) have concluded that the majority of evidence shows CR magnitude to be a positive function of CS intensity. In the present study, the finding that a strong $S_{1}$ led to a significantly greater suppression effect than a mild $S_{1}$ seems to indicate that this same relationship may indeed occur in SPC.

In CER conditioning, Kamin (1961) found that the amount of suppression was inversely related to the length of the trace interval. The second finding of the present investigation, unlike Kamin's (1961) results, revealed that trace-interval variations during preconditioning had no significant effect on suppression. However, it appears that there is an ISI by Trace Interval interaction in CER conditioning (Kamin, 1965). That is, delay and trace conditioning procedures do not produce any significant differences in suppression, provided the ISI is "favorably close" to the US; yet, when the ISI is "too far" from the US, the delay procedure is significantly superior to short and long trace procedures, and the short trace procedure in turn is significantly superior to the long trace procedure. Therefore, if, as Kamin (1965) says, the 3-min ISI used in Kamin's (1961) study is beyond the optimum range for CER conditioning and if the 10-sec ISI used in the present study can be accepted as within the optimum range for SPC, then, unlike the effect obtained by Kamin (1961), the trace-interval manipulations in the present study should not have produced any significant differences in suppression. The fact that no significant effect was obtained, therefore, seems to indicate that trace-interval effects in SPC and classical conditioning are similar when the ISI is close to optimum.

Given that comparable parametric work in SPC and classical conditioning can provide the basis for a decision as to their equivalence, the present findings lend additional empirical support to the notion that classical conditioning occurs during the preconditioning phase of the SPC procedure.

\section{REFERENCES}

Gormezano, I., \& Moore, J. W. Classical conditioning. In M. H. Marx (Ed.), Learning: Processes. London: Collier-Macmillan, 1969.

Holmes, P. A. The effect of stimulus intensity and unconditioned responsivity on sensory preconditioning using the CER. Unpublished doctoral dissertation, University of Delaware, 1968.

Kamin, L. J. Trace conditioning of the conditioned emotional 
response. Journal of Comparative \& Physiological Psychology , $1961,54,149-153$.

Kamin, L. J. Temporal and intensity characteristics of the conditioned stimulus. In W. J. Prokasy (Ed.), C'lassical conditioning: A symposium. New York: Appleton-Century-Crofts, 1965.

Osgood, C. E. Method and theory in experimental psychology. New York: Oxford University Press, 1953.

Prewitt, E. P. Number of preconditioning trials in sensory preconditioning using CER training. Journal of Comparative \& Physiological Psychology, 1967, 64, 360-362.

Tait, R. W., Black, M., Katz, M., \& Suboski, M. D. Discriminative sensory preconditioning. Canadian Journal of Psychology, 1972, 26, 201-205.

Tait, R. W., Marquis, H. A., Williams, R., Weinstein, L., \&
Suboski, M. D. Extinction of sensory preconditioning using CER training. Journal of Comparative \& Physiological Psychology, 1969, 69, 170-172.

Tait, R. W., \& Suboski, M. D. Stimulus intensity in sensory preconditioning of rats. Canadian Journal of Psychology, 1972 , in press.

Thornton, G. L. The effect of stimulus intensity upon sensory preconditioning. Proceedings of the Iowa Academy of Science, 1956, 63, 620-626. (Psychological Abstracts, 1958, 32, No. 3869 .)

Wokoum, F. W. The effect of stimulus intensity in sensory preconditioning. Unpublished doctoral dissertation, University of Nebraska, 1959.

(Received for publication November 6, 1972.) 